Information Center Web Portals. Journal Service Science \& Management. № 3. P. 168-180

DOI: https://doi.org/10.4236/jssm.2009.23020

5. Hrabovskyi Y., Fedorchenko V. (2019). Development of the optimization model of the interface of multimedia edition. EUREKA: Physics and Engineering. № 3, pp. 3 - 12. DOI: $10.21303 / 2461-$ 4262.2019.00902

6. Hrabovskyi Y. (2018). Proektuvannia intelektualnoho korystuvatskoho interfeisu system pidtrymky elektronnoho navchannia. [Designing the Intelligent User Interface of E-Learning Support Systems]. Scientific Journal "ScienceRise". No. 11 (52). Pp. 36-39

7. Martins P., Zacarias M. A. (2017). Web-based Tool for Business Process Improvement. International Journal of Web Portals. 2017. Volume 9. Issue 1. P. $68-84$ DOI: https://doi.org/10.4018/IJWP.2017070104

8. Grabovsky E. M. (2019). Analiz vy`kory`stannya mul`ty`medijny`x komponentiv $\mathrm{v}$ suchasny` $\mathrm{x}$ texnologiyax mobil nogo navchannya. [Analysis of the use of multimedia components in modern technologies of mobile learning]. Scientific Journal "ScienceRise". No. 4 (57), pp. 46-50. 9. Naumenko M. O. (2018). Vdoskonalennya upravlinnya yakistyu produkciyi vy`sokotexnologichny`x pidpry`yemstv. [Improvement of product quality management of high-tech enterprises. Bulletin of the Economics of Transport and Industry. No. 62, pp. 335 - 342.

10. Kalycheva N.Ie., Maslova V.O. (2014) Lohistychni pidkhody, yak osnova ratsionalnoi orhanizatsii vyrobnychoho protsesu na pidpryiemstvi [Logistic approaches as a basis for rational organization of production process at the enterprise]. Bulletin of Economics of Transport and Industry. No. 47. Pp. 83 - 86.

11. Kalycheva N.Ie., Kopachevska Yu. A. (2018) Vplyv lohistyky na rozvytok pidpryiemstv maloho biznesu $\mathrm{v}$ suchasnykh umovakh hospodariuvannia. [The influence of logistics on the development of small business in modern conditions of management]. UzhNU Scientific Bulletin. Series: International Economic Relations and the World Economy. Issue 20. Part 2. Pp. 11 14.

УДК 658.7.1

\title{
УПРАВЛІННЯ ПРОЦЕСАМИ ВЗАЕМОДІЇ 3 ПОСТАЧАЛЬНИКАМИ В СИСТЕМІ МАТЕРІАЛЬНО-ТЕХНІЧНОГО ЗАБЕЗПЕЧЕННЯ ВІЙСЬКОВИХ ПІДРОЗДІЛІВ НАЦІОНАЛЬНОЇ ГВАРДІЇ УКРАЇНИ
}

\author{
Товма Л. Ф., к.м.н., ст. викладач, \\ Товма О. А., к.е.н., доцент (НАНГУ)
}

У даній статті подано методику управління процесами взаємодіі 3 постачальниками в системі матеріально-технічного забезпечення військових підрозділів Національної гвардї України. Розглянуто основні заходи стратегічного рівня прийняття управлінських рімень стосовно взаємодії з постачальниками. Запропонована схема рівнів системи прийняття управлінських рімень щзодо управління процесами взаємодї з постачальниками в системі матеріально-технічного забезпечення військових підрозділів Національної гвардії України. Розроблено перелік критеріїв, за якими можна оцінити необхідність встановлення партнерства з певними

(C) Товма Л.Ф.,

Товма O.A.

Вісник економіки транспорту і промисловості № 69, 2020 
групами постачальників. Запропоновано схему розрахунку інтегральної оцінки вибору постачальників.

Ключові слова: постачальник, матеріально-технічне забезпечення, військові підрозділи, методика, процес, управлінські рішення

\title{
УПРАВЛЕНИЕ ПРОЦЕССАМИ ВЗАИМОДЕЙСТВИЯ С ПОСТАВЩИКАМИ В СИСТЕМЕ МАТЕРИАЛЬНО- ТЕХНИЧЕСКОГО ОБЕСПЕЧЕНИЯ ВОЕННЫХ ПОДРАЗДЕЛЕНИЙ НАЦИОНАЛЬНОЙ ГВАРДИИ УКРАИНЫ
}

\author{
Товма Л. Ф., к.т.н., ст. преподаватель, \\ Товма О. А., к.э.н., доцент (НАНГУ)
}

В данной статье представлена методика управления проиессами взаимодействия с поставщиками в системе материально-технического обеспечения военных подразделений Национальной гвардии Украины. Рассмотрены основные мероприятия стратегического уровня принятия управленческих решений по взаимодействию с поставщиками. Предложена схема уровней системь принятия управленческих решений по управлению процессами взаимодействия с поставщиками в системе материально-технического обеспечения военных подразделений Национальной гвардии Украины. Разработан перечень критериев, по которым можно оценить необходимость установления партнерства с определенными группами поставщиков. Предложена схема расчета интегральной оченки выбора поставщиков.

Ключевые слова: поставщик, материально-техническое обеспечение, военные подразделения, методика, процесс, управленческие решения

\section{MANAGEMENT OF PROCESSES OF INTERACTION WITH SUPPLIERS IN THE SYSTEM OF MATERIAL AND TECHNICAL SUPPLY OF MILITARY UNITS OF THE NATIONAL GIVARIAN}

\author{
Tovma L., Candidate of Technical Sciences, Senior Lecturer, \\ Tovma O., Ph.D., Associate Professor (NANGU)
}

This article describes the methodology of managing the processes of interaction with suppliers in the system of logistical support of military units of the National Guard of Ukraine. Two modules of the system of logistics management of military units are proposed. The article assumes that the strategic module should support the decision to choose strategic partners for long-term relationships. The tactical module in the context of this article should support the decision to choose tactical partners for short-term relationships. The basic measures of strategic level of decision-making in relation to interaction with suppliers are considered. The scheme of levels of decision-making system for management of processes of interaction with suppliers in the system of logistical support of military units of the National Guard of Ukraine is proposed. Particular attention is paid to support decision-making on the feasibility of establishing long-term relationships with suppliers of each type of purchased resource. A list of criteria for assessing the need to partner with specific groups of suppliers has been developed. The article states that decision support for choosing a strategic partner among suppliers is done by evaluating the user (or expert) against the relevant criteria. In the work the general scheme of criteria of evaluation of suppliers is created. The scheme of 
calculation of the integral estimation of a choice of suppliers is offered. The article formalizes the task of managing the system of logistical support of the military units of the National Guard of Ukraine with the choice of the supplier of resources. The proposed methodology for managing the processes of interaction with suppliers in the system of logistics of the military units of the National Guard of Ukraine is a methodological and theoretical basis for the creation of an appropriate information support system for decision-making regarding the optimization of logistics processes. The practical significance of the developed methodology is to provide specific recommendations to the command of military units of the National Guard of Ukraine on managing the processes of interaction with suppliers in the logistics system. decisions.

Key words. supplier, logistics, military units, methodology, process, management

\section{Постановка}

Необхідною передумовою ефективного здійснення забезпечення Національної матеріально-технічного військових підрозділів гвардії України цілеспрямована та результативна взаємодія 3 постачальниками всіх видів ресурсів. Управління процесами взаємодії 3 постачальниками в системі матеріальнотехнічного забезпечення військових підрозділів має забезпечити надійний логістичний ланцюжок взаємопов'язаних операцій, які в комплексі повинні гарантувати позитивний результат як для замовника, так і для постачальників [1].

Аналіз останніх досліджень $i$ публікацій. У роботах [2-4] аналізуються та пропонуються різні підходи до управління інформаційними потоками логістичних процесів. Аналіз питань якості управління взаємодією 3 постачальниками знайшов свого відображення в дослідженнях [5-7]. Ключові аспекти інформаційної підтримки процесів взаємодії 3 постачальниками систематизовані в наукових статтях [8-10].

Виділення невирішених частин загальної проблеми. Однак на сьогодні в спеціалізованій літературі відсутня цілісна методика моніторингу взаємодії 3 постачальниками військових підрозділів Національної гвардії України.

$\begin{array}{lcr}\text { Mетою } & \text { даної } & \text { cmammi } \\ \text { розроблення } & \text { методики } & \text { управління }\end{array}$

процесами взаємодії з постачальниками в системі матеріально-технічного забезпечення військових підрозділів Національної гвардії України.

Викладення основного матеріалу дослідження. Стратегічний рівень прийняття управлінських рішень повинен включати в себе такі етапі, як:

1) визначення необхідності встановлення довгострокових партнерських відносин в рамках кожної групи постачальників;

2) вибір стратегічних партнерів в рамках кожної групи постачальників.

Схема рівнів системи прийняття управлінських рішень взаємодії 3 постачальниками в системі матеріальнотехнічного забезпечення військових підрозділів Національної гвардії України зображена на рис. 1.

Тактичний рівень представляє собою вибір постачальників для встановлення безособових відносини, та такі системи повинні надавати користувачеві допомогу 3 вибору постачальників за принципом економічної доцільності в короткостроковій та середньостроковій перспективі.

На основі вищезгаданих вимог до систем підтримки прийняття рішень, в сфері управління відносинами військових підрозділів з постачальниками сформуємо комплекс функціональних вимог до такої системи. 


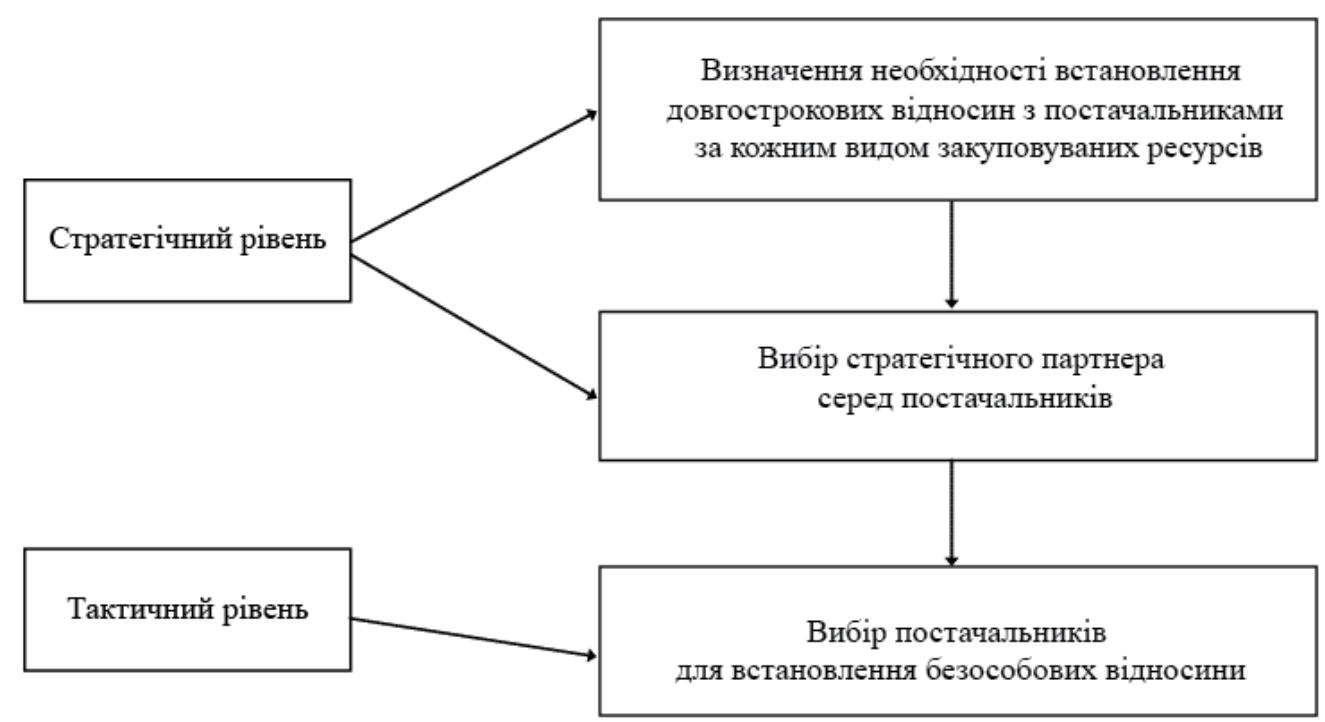

Рис. 1. Схема рівнів системи прийняття управлінських рішень щодо управління прочесами взаємодії з постачальниками в системі матеріально-технічного забезпечення військових підрозділів Національної гвардії Украӥни

Підсистема відносинами військових підрозділів 3 постачальниками має складатися 3 двох модулів:

1) стратегічний підтримувати рішення щодо вибору стратегічних партнерів довгострокових відносин;

2) тактичний модуль підтримувати рішення щодо вибору тактичних партнерів

для
Функції стратегічного модуля:

1) Підтримка прийняття рішення 3 доцільності установлення довгострокових відносин 3 постачальниками кожного 3 видів закуповуваного ресурсу.

Для реалізації даної призначений перелік критеріїв, за якими можна оцінити необхідність встановлення партнерства 3 певними групами постачальників (табл. 1). Таблиия 1

Критерії вибору відносин з постачальниками

\begin{tabular}{|c|c|c|}
\hline $\begin{array}{c}\text { Характеристики купованого } \\
\text { продукту }\end{array}$ & $\begin{array}{c}\text { Значення характеристик, } \\
\text { при яких доцільно будувати } \\
\text { партнерські відносини з } \\
\text { постачальником }\end{array}$ & $\begin{array}{c}\text { Значення характеристик, } \\
\text { при яких не доцільно } \\
\text { будувати партнерські } \\
\text { відносини } 3 \\
\text { постачальником }\end{array}$ \\
\hline \multicolumn{3}{|c|}{ Фактори рівня вимог до постачальника } \\
\hline обсяг закупівель & високий & не високий \\
\hline важливість продукту & висока & не високий \\
\hline $\begin{array}{l}\text { ступінь індивідуалізації } \\
\text { продукту }\end{array}$ & високий & не висока \\
\hline \multicolumn{3}{|c|}{ Фактори ризику поставок } \\
\hline $\begin{array}{l}\text { співвідношення попиту і } \\
\text { пропозиції на ринку }\end{array}$ & пропозиція менше попиту & $\begin{array}{l}\text { пропозиція перевищує } \\
\text { попит }\end{array}$ \\
\hline \multicolumn{3}{|c|}{ Фактори складності зміни постачальника } \\
\hline $\begin{array}{l}\text { технічна комплексність } \\
\text { (складність) продукту }\end{array}$ & висока & не висока \\
\hline
\end{tabular}


2) Підтримка прийняття рішення з вибору стратегічного партнера серед постачальників.

Для реалізації даної функції система менеджменту на стратегічному рівні партнерських відносин повинна надавати можливість оцінювання користувачем (або експертом) за наступними критеріями, представленими в таблиці 2.

Таблиия 2

Вибір стратегічного партнера

\begin{tabular}{|c|c|}
\hline Показники & $\begin{array}{c}\text { Оцінювання (за } \\
10 \text { бальною } \\
\text { шкалою) }\end{array}$ \\
\hline 1 & 2 \\
\hline \multicolumn{2}{|l|}{ ХАРАКТЕРИСТИКИ ПОСЛУГ ПОСТАЧАЛЬНИКА } \\
\hline \multicolumn{2}{|l|}{ якість } \\
\hline \multicolumn{2}{|l|}{ оперативність } \\
\hline \multicolumn{2}{|l|}{ широта асортименту } \\
\hline \multicolumn{2}{|l|}{ політика в сфері розрахунків за продукцію (ціни, знижки, кредити) } \\
\hline \multicolumn{2}{|l|}{ ХАРАКТЕРИСТИКИ ПОСТАЧАЛЬНИКА } \\
\hline \multicolumn{2}{|l|}{ А. Надійність постачальника } \\
\hline \multicolumn{2}{|l|}{ фінансові характеристики } \\
\hline \multicolumn{2}{|l|}{ рентабельність постачальника } \\
\hline \multicolumn{2}{|l|}{ фінансова стійкість постачальника } \\
\hline \multicolumn{2}{|l|}{ кредитна історія } \\
\hline \multicolumn{2}{|l|}{ високий виробничий потенціал постачальника } \\
\hline \multicolumn{2}{|l|}{ рівень технічного забезпечення } \\
\hline \multicolumn{2}{|l|}{ рівень технологічного забезпечення } \\
\hline \multicolumn{2}{|l|}{ якість продукції } \\
\hline \multicolumn{2}{|l|}{ Б. Здатність постачальника до розвитку і зміни } \\
\hline \multicolumn{2}{|l|}{ високий інвестиційно-інноваційний потенціал постачальника } \\
\hline \multicolumn{2}{|l|}{ здатність персоналу до навчання та перенавчання } \\
\hline \multicolumn{2}{|l|}{ В. якість управління } \\
\hline \multicolumn{2}{|l|}{ якість стратегічного і тактичного управління підприємством } \\
\hline \multicolumn{2}{|l|}{ Г. Надійність відносин з постачальником } \\
\hline \multicolumn{2}{|l|}{ репутація підприємства як партнера, що виконує зобов'язання } \\
\hline Д. Готовність до діалогу, готовність йти на компроміс & \\
\hline
\end{tabular}


Функції тактичного модуля. Для реалізації даної функції система підтримки прийняття рішень на тактичному рівні безособових відносин повина надавати користувачеві допомогу 3 вибору постачальників за принципом економічної доцільності короткостроковій та середньостроковій перспективі. Можливість оцінювання постачальника надається за наступними критеріями:

1) цінова політика;

2) можливості товарного

кредиту;

3) можливості відстрочки

платежу;

4) знижки;

5) знижки при великих обсягах замовлення;

6) накопичувальні знижки;

7) оперативність поставок;

8) широта асортименту;

9) використання технології

CRM;

10) ступінь дружби 3 виробником;

11) технічне оснащення тестових лабораторій;

12) швидкість реагування на проблеми;

13) додаткові послуги;

14) філії у великих обласних центрах та дилерська мережа;
15) використання математичних методів прогнозування обсягу закупівель;

16) продумана логістика;

17) можливість індивідуального замовлення у виробника;

18) кваліфікованість спеціалістів продавця;

19) можливість отримання допомоги з ремонтом у виробника;

20) допомога в порівнянні варіантів комплекції;

21) аналіз клієнтської бази;

22) поради (курси, тренінги) 3 навчання персоналу;

23) можливість відвідування демонстраційного залу компанії;

24) програма підвищення кваліфікації;

25) гарантійні зобов'язання;

26) профілактичні перевірки машини.

При оцінюванні постачальників необхідно враховувати вплив їх характеристик на наступні показники:

1) продуктивність;

2) якість продукції;

3) гнучкість, оперативність;

4) економія витрат;

5) підтримання

платоспроможності.

У зв'язку з цими критеріями оцінки постачальників формують ієрархічну систему. На рис. 2 продемонстрована загальна схема оцінки постачальників.

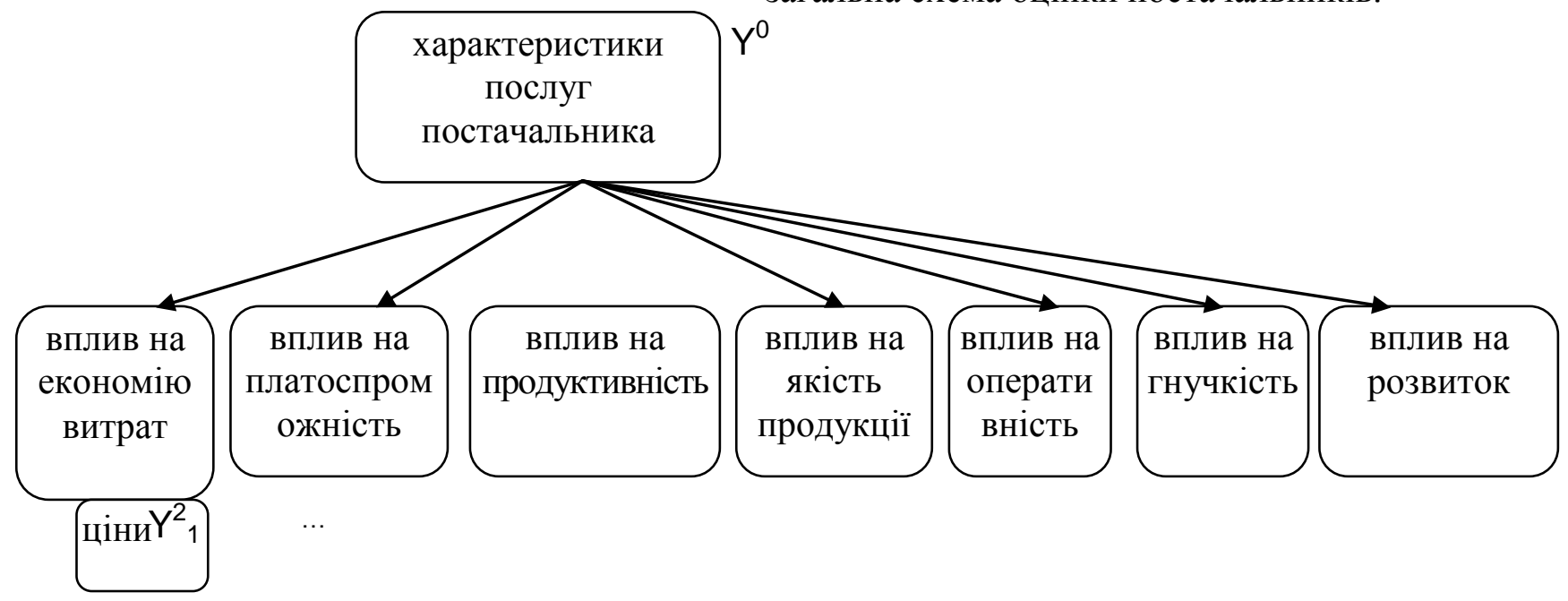

Рис. 2. Загальна схема критеріїв очүінки постачальників 
Формула для розрахунків інтегральної оцінки має наступній вигляд:

$$
\mathrm{Y}^{0}=\sum_{i} \mathrm{~V}_{i}^{*} \mathrm{Y}_{i}^{1}
$$

де $\mathrm{Y}^{0}$ — інтегральна оцінка;

$\mathrm{Y}_{i}^{1}$ - оцінка впливу характеристик

постачальника на і-тий показник діяльності військових підрозділів;

$\mathrm{V}_{i}$ - коефіцієнт важливості і-го

показника діяльності військових підрозділів.

$$
\mathrm{Y}^{0}=\sum_{j} \mathrm{a}_{i j} * \mathrm{Y}_{j}^{2},{ }_{i}^{1}
$$

де $\mathrm{Y}_{j}^{2}-$ оцінка постачальника за критерієм j;

$\mathrm{a}_{i j}$ - коефіцієнт важливості j -го критерію відносно і-го показника діяльності військових підрозділів.

Таким чином, задача системи менеджменту 3 вибору постачальника являє собою пару <A, K>, де А розглянуті постачальники, К інтегральній критерій оцінки постачальників.

Висновок. Запропонована методика управління процесами взаємодії 3 постачальниками в системі матеріальнотехнічного забезпечення військових підрозділів Національної гвардії України становить методичне та теоретичне підгрунтя для створення відповідної інформаційної системи підтримки прийняття рішень стосовно оптимізації логістичних процесів.

Практичною

розробленої методики $є$ надання конкретних рекомендацій командуванню військових підрозділів Національної гвардії України щодо управління процесами взаємодії з постачальниками в системі матеріально-технічного забезпечення.

\section{ПЕРЕЛІК ВИКОРИСТАНИХ ДЖЕРЕЛ}

1. Каличева Н.Є., Маслова В.О. Логістичні підходи, як основа раціональної організації виробничого процесу на підприємстві. Вісник економіки транспорту і промисловості. 2014. № 47. C. 83 - 86 .

2. Hrabovskyi Y., Yevsyeyev O. Development of methodological principles of support-preservation engineering work. Технолоічний аудит $i$ резерви виробнищтва. 2018. №2/2. С. 43-49

3. Соколовський С. А, Науменко М. О. Аналіз особливостей управління інформаційними потоками логістичних процесів підрозділів Національної гвардії України. ScienceRise. 2018. № 2. C. 1921.

4. Науменко М.О., Рига О.С. Підходи до забезпечення стратегічного управління підприємств в умовах нестійкого середовища. Вісник економіки транспорту і промисловості. 2018. № 63. C. 216-223.

5. Hrabovskyi Y., Fedorchenko V., Development of the optimization model of the interface of multimedia edition, EUREKA: Physics and Engineering, № 3, pp. 3 - 12, 2019. DOI: 10.21303/24614262.2019 .00902

6. Науменко М.О. Вдосконалення управління якістю продукції високотехнологічних підприємств. Вісник економіки транспорту i промисловості. 2018. № 62. С. 335-342.

7. Грабовський Є.M. Методика вибору обладнання флексографічного друку для виготовлення етикеточної продукції. Системи обробки інформаџіiі. 2017. № 2(148). С. 216 - 223.

8. Martins P., Zacarias M. A Webbased Tool for Business Process Improvement. International Journal of Web Portals. 2017. Volume 9. Issue 1. P. $68-84$ DOI: https://doi.org/10.4018/IJWP.2017070104

9. Hu C., Yang Z, Mingjing G. AHP and CA Based Evaluation of Website 
Information Service Quality: An Empirical Study on High-Tech Industry Information Center Web Portals. Journal Service Science \& Management. 2009. № 3. P. 168-180 DOI: https://doi.org/10.4236/jssm.2009.23020

10. Pushkar O., Hrabovskyi Y. Methodology for developing an intelligent user interface for educational publications in the e-learning system. Development Management. 2019. № 17(3). P. 23-34. Doi:10.21511/dm.17(3).2019.03

\section{REFERENCES}

1. Kalycheva N.Ie., Maslova V.O. (2014) Lohistychni pidkhody, yak osnova ratsionalnoi orhanizatsii vyrobnychoho protsesu na pidpryiemstvi [Logistic approaches as a basis for rational organization of production process at the enterprise]. Bulletin of Economics of Transport and Industry. No. 47. Pp. $83-86$.

2. Hrabovskyi Y. Yevsyeyev O. (2018) Development of methodological principles of support-preservation engineering work. Технолоічний аудит $i$ резерви виробництва. 2018. №2/2. Рp. 4349.

3. Sokolovskyi S. A., Naumenko N. A. (2018). Analiz osobly`vostej upravlinnya informacijny`my` potokamy` logisty`chny`x procesiv pidrozdiliv Nacional noyi gvardiyi Ukrayiny. [Analysis of peculiarities of management of information flows of logistic processes of units of the National Guard of Ukraine]. ScienceRise. No 2, pp. 19-21.

4. Naumenko M. O., Riga O. S. (2018). Pidxody do zabezpechennya strategichnogo upravlinnya pidpry`yemstv $\mathrm{v}$ umovax nestijkogo seredovy`shha [Approaches to providing strategic management of enterprises in an environment of unstable environment] Bulletin of the Economics of Transport and Industry of the UGCC. No. 63, pp. $216-223$.

5. Hrabovskyi Y., Fedorchenko V. (2019) Development of the optimization model of the interface of multimedia edition. EUREKA: Physics and Engineering. № 3. Pp. 3 - 12. DOI: 10.21303/24614262.2019.00902.

6. Naumenko M. O. (2018). Vdoskonalennya upravlinnya yakistyu produkciyi vy`sokotexnologichny`x pidpry yemstv. [Improvement of product quality management of high-tech enterprises.

Bulletin of the Economics of Transport and Industry. No. 62, pp. $335-342$.

7. Hrabovskyi Ye.M. (2017)Metodyka vyboru obladnannia fleksohrafichnoho druku dlia vyhotovlennia etyketochnoi produktsii [Methods of choosing flexographic printing equipment for the production of label products]. Information processing systems. No. 2 (148). Pp. 216 - 223.

8. Martins P., Zacarias M. A (2017)Web-based Tool for Business Process Improvement. International Journal of Web Portals. Volume 9. Issue 1. P. 68 - 84 DOI: https://doi.org/10.4018/IJWP.2017070104

9. Hu C., Yang Z, Mingjing G. (2009) AHP and CA Based Evaluation of Website Information Service Quality: An Empirical Study on High-Tech Industry Information Center Web Portals. Journal Service Science \& Management. № 3. P. 168-180 DOI: https://doi.org/10.4236/jssm.2009.23020

10. Pushkar O., Hrabovskyi Y. (2019) Methodology for developing an intelligent user interface for educational publications in the e-learning system. Development Management. № 17(3). P. 23-34. Doi:10.21511/dm.17(3).2019.03 